\title{
Investigation by AES, EELS and TRIM Simulation Method of InP(100) Subjected to $\mathrm{He}^{+}$and $\mathrm{H}^{+}$Ions Bombardment
}

\author{
Mohamed Ghaffour ${ }^{1}$, Abdellaoui Abdelkader ${ }^{1}$, Abdellah Ouerdane ${ }^{1}$, M'Hammed Bouslama ${ }^{1}$, \\ Christian Jardin ${ }^{2}$ \\ ${ }^{1}$ Materials Laboratory, LABMAT, High School of Technical Studies, ENSET d'Oran, Oran M'naouar, Algeria; ${ }^{2}$ Technical \\ University Institute, Lyon I, France \\ Email: aekabdellaoui@yahoo.fr
}

Received March $4^{\text {th }}, 2011$; revised March $16^{\text {th }}, 2011$; accepted May $6^{\text {th }}, 2011$.

\begin{abstract}
Auger Electron Spectroscopy (AES) and Electron Energy Loss Spectroscopy (EELS) have been performed in order to investigate the InP(100) surface subjected to ions bombardment. The InP(100) surface is always contaminated by carbon and oxygen revealed by C-KLL and O-KLL AES spectra recorded just after introduction of the sample in the UHV spectrometer chamber. The usually cleaning process of the surface is the bombardment by argon ions. However, even at low energy of ions beam ( $300 \mathrm{eV})$ indium clusters and phosphorus vacancies are usually formed on the surface. The aim of our study is to compare the behaviour of the surface when submitted to $\mathrm{He}^{+}$or $\mathrm{H}^{+}$ions bombardment. The helium ions accelerated at $500 \mathrm{~V}$ voltage and for $45 \mathrm{mn}$ allow removing contaminants but induces damaged and no stoichiometric surface. The proton ions were accelerated at low energy of $500 \mathrm{eV}$ to bombard the InP surface at room temperature. The proton ions broke the In-P chemical bonds to induce the formation of In metal islands. Such a chemical reactivity between hydrogen and phosphorus led to form chemical species such as $\mathrm{PH}$ and $\mathrm{PH}_{3}$, which desorbed from the surface. The chemical susceptibly and the small size of $\mathrm{H}^{+}$advantaged their diffusion into bulk. Since the experimental methods alone were not able to give us with accuracy the disturbed depth of the target by these ions. We associate to the AES and EELS spectroscopies, the TRIM (Transport and Range of Ions in Matter) simulation method in order to show the mechanism of interaction between $\mathrm{Ar}^{+}, \mathrm{He}^{+}$or $\mathrm{H}^{+}$ions and InP and determine the disturbed depth of the target by argon, helium or proton ions.
\end{abstract}

Keywords: AES, EELS, Interaction Ions-Matter, Simulation Method TRIM, InP

\section{Introduction}

$\mathrm{InP}$ is expected to be a promising material for both high-speed electrical and optoelectronic device application, in large part due to its high mobility. The most of these applications, metal-InP Schottky structures of good quality is required [1-4]. The nature and quality of surface preparation in semiconductor technology is of the utmost importance during device fabrication and has a pronounced influence on the performance of these devices [5-8].

Many woks have been done concerning the study of InP compound in order to understand the origin of the instabilities of components so elaborated from this compound. The most important results so found are the instability of
InP against all physical treatment such as the sputter etching by $\mathrm{Ar}^{+}$ion bombardment or heating in UHV [9-12].

The aim of our study is to compare the behaviour of the surface when subjected to $\mathrm{He}^{+}$or $\mathrm{H}^{+}$ions comparatively to the $\mathrm{Ar}^{+}$ions bombardment, which is usually used to clean surfaces. In this interest, we use the spectroscopy methods such as the Auger Electron Spectroscopy (AES) and the Electron Energy Loss Spectroscopy (EELS). So, we present some results about the effect of $\mathrm{H}^{+}$and $\mathrm{He}^{+}$ions bombardment on the $\operatorname{InP}(100)$ surface. However, because it is difficult to determine the affected depth of the surface by ions, we combine these analysis techniques with the simulation method TRIM (Transport and Range of Ions in Matter) to determine the affected depth of the InP surface as a function of the ions energy. 


\section{Experimental}

The Auger electron spectra (AES) and electron energy loss (EELS) were performed by using an hemispherical spectrometer. For the best compromise between the transmission and the resolution of the apparatus [13], we use constant pass energy of $80 \mathrm{eV}$ between the deflectors of the analyzer operating in direct mode $\mathrm{N}(\mathrm{E})$. The $\mathrm{InP}(100)$ surface was characterized by AES (electron beam of $3 \mathrm{KeV}$, with a low current density $\mathrm{Jp}=10^{-3}$ $\mathrm{A} \cdot \mathrm{cm}^{-2}$ ). The incident electron beam was focussed onto an area of $1 \mathrm{~mm}$ of diameter. These routine parameters were choose in order to reduce the effect of the electron beam on the material surface and may be changed when needed. An ion pump associated with a cooled titanium sublimator assured a bass pressure of $10^{-9}$ torr.

Before loading in the UHV chamber, the $\operatorname{InP}(100)$ samples were chemically cleaned with successively pure $\mathrm{H}_{2} \mathrm{SO}_{4}$ acid, $3 \% \mathrm{Br}_{2}$ solution in $\mathrm{CH}_{3} \mathrm{OH}$ and finally rinsed in deionised water and methanol bath [14].

\section{Results and Discussion}

The remaining contamination layer on the sample was mainly composed of carbon and oxygen as revealed by the first recorded AES spectra (C-KLL and O-KLL) [15-17]. The sample was sputter-cleaned, as usual, by a normal incidence $\mathrm{Ar}^{+}$ion beam at low energy of $500 \mathrm{eV}$ with a current density of about $2 \times 10^{-6} \mathrm{~A} \cdot \mathrm{cm}^{-2}$ to remove these contaminants. The argon pressure was in the range of $10^{-5}$ torr. Consequently, a system labelled (In; InP) results from such cleaning, where In is the metallic indium as clusters distributed on the InP surface. Furthermore, the argon ion bombardment of InP surface induces a superficial roughness which affects the EELS spectra as reported by other authors [18-20].

\subsection{Action of $\mathrm{He}^{+}$Ions Bombardment on $\operatorname{InP}(100)$}

Can we avoid the degradation of the surface by replacing the argon ions by helium ions of the same chemical inertness but small sizes? Just after introduction of the sample in the UHV chamber of the spectrometer, we have recorded the AES spectrum of the contaminated surface as shown in Figure 1(a).

The contaminants are mainly carbon and oxygen. In order to remove these contaminants, we have submitted the InP surface to $\mathrm{He}^{+}$ions bombardment for $15 \mathrm{mn}$ at $500 \mathrm{~V}$ accelerated voltage. Figure 1(b) shows the cleaned surface of $\operatorname{InP}(100)$.

But this cleaning effect is also accompanied by the formation of indium metal as shown in fine structure of AES spectra of indium In- $\mathrm{M}_{45} \mathrm{~N}_{45} \mathrm{~N}_{45}$ recorded in Figure 2.

The Auger spectra shape varies as a function of bom-

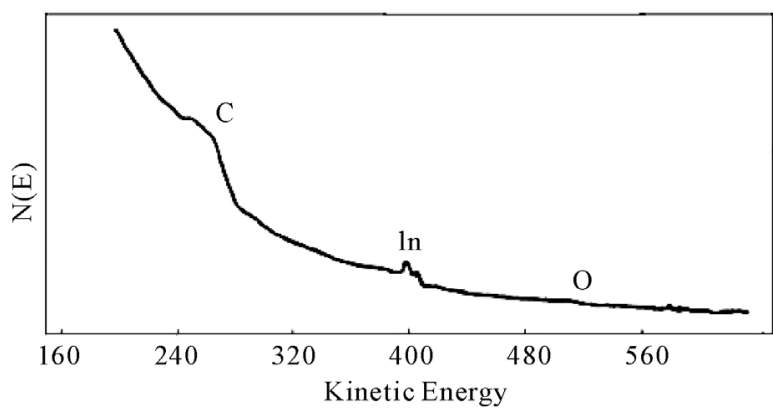

(a)

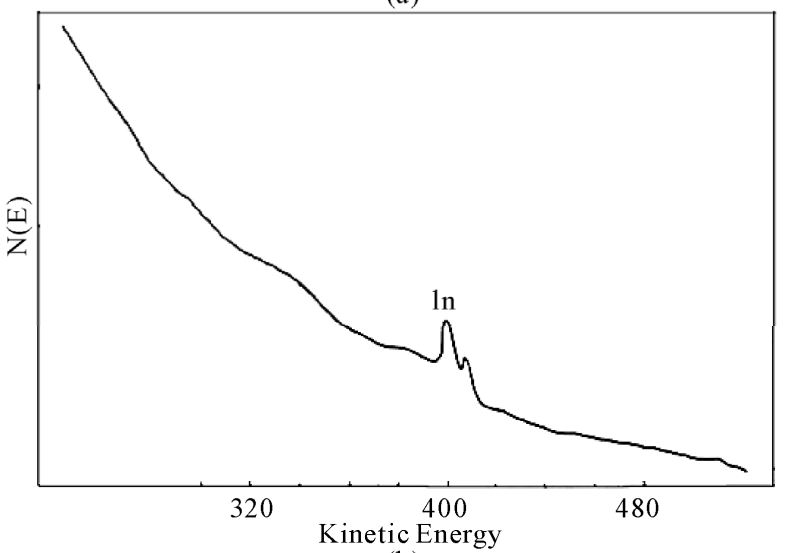

(b)

Figure 1. (a) Contaminated surface of $\operatorname{InP}(100)$ just after its introduction in UHV spectrometer chamber; (b) Decontamination of the surface by the $\mathrm{He}^{+}$ions.

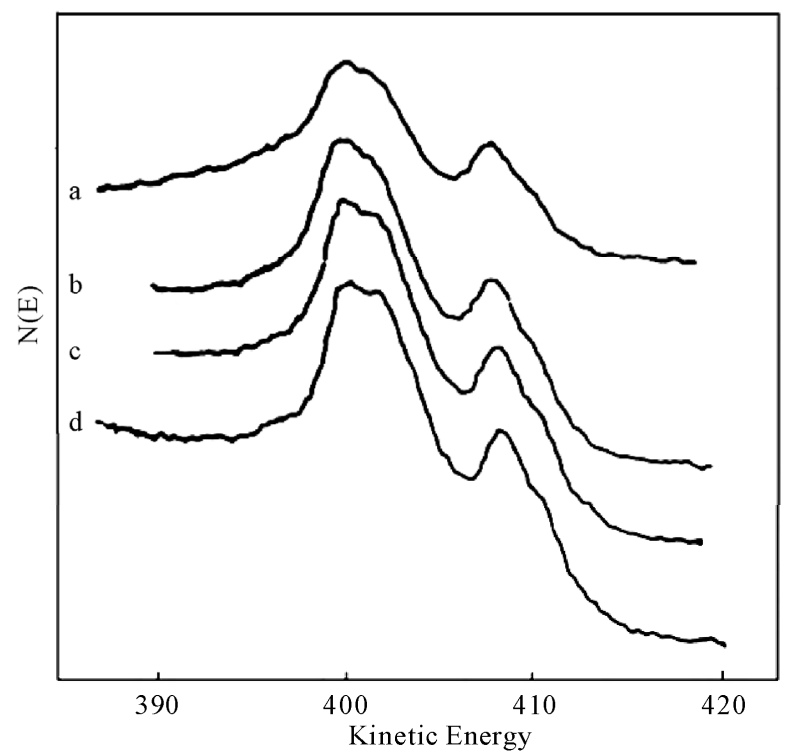

Figure 2. Evolution of In-MNN Auger spectra of indium during the $\mathrm{He}^{+}$ions bombardment. a) just after introduction of the sample in the UHV chamber, b), c) and d) after 5, 10 and $15 \mathrm{mn}$ time ions bombardment.

bardment time of the surface. Indeed, there develops a peak related to the chemical bond of metallic In. This 
metallic indium is resulted from the broken of chemical bonds (In-P) and distributed on the surface as clusters.

This result is confirmed by the EELS spectra shown in the Figure 3. These spectra are recorded by varying the primary energy Ep. We show in this figure the appearance of characteristic peaks of metallic indium. The energy loss peaks related to surface and bulk plasmons of In metal locate clearly at $8.6 \mathrm{eV}$ and $11.6 \mathrm{eV}$. These peaks are more pronounced in the spectrum $b$ ) because of low primary energy comparatively to the a) one. The low primary energy concerns the first layers of the surface.

\subsection{Action of $\mathrm{H}^{+}$Bombardment on $\operatorname{InP}(100)$}

We bombard the surface of $\operatorname{InP}(100)$ by proton ions accelerated by a voltage of $500 \mathrm{~V}$. Preferential etching of phosphorus and the formation of indium metal is observed. There is desorption of chemical species as demonstrated by A. Porte and al. [21-22] with a mass spectrometer. These observations also coincides with those of F. Proix and al. [23] who studied the interaction of atomic and ionized hydrogen with cleaved surfaces of $\operatorname{InP}(110)$.

Figure 4 shows the In- $\mathrm{M}_{45} \mathrm{~N}_{45} \mathrm{~N}_{45}$ AES spectra of InP when bombarded by $\mathrm{H}^{+}$ions. The spectrum $\mathrm{b}$ ) involves the formation of a characteristic peak of metallic indium.

The recorded EELS spectra at the same experimental conditions of the Figure 5 confirm this result. Indeed, the formation of the peaks located at $8.6 \mathrm{eV}$ and $11.6 \mathrm{eV}$ related respectively to surface and bulk plasmons of metallic indium appears clearly on the spectrum b) of the

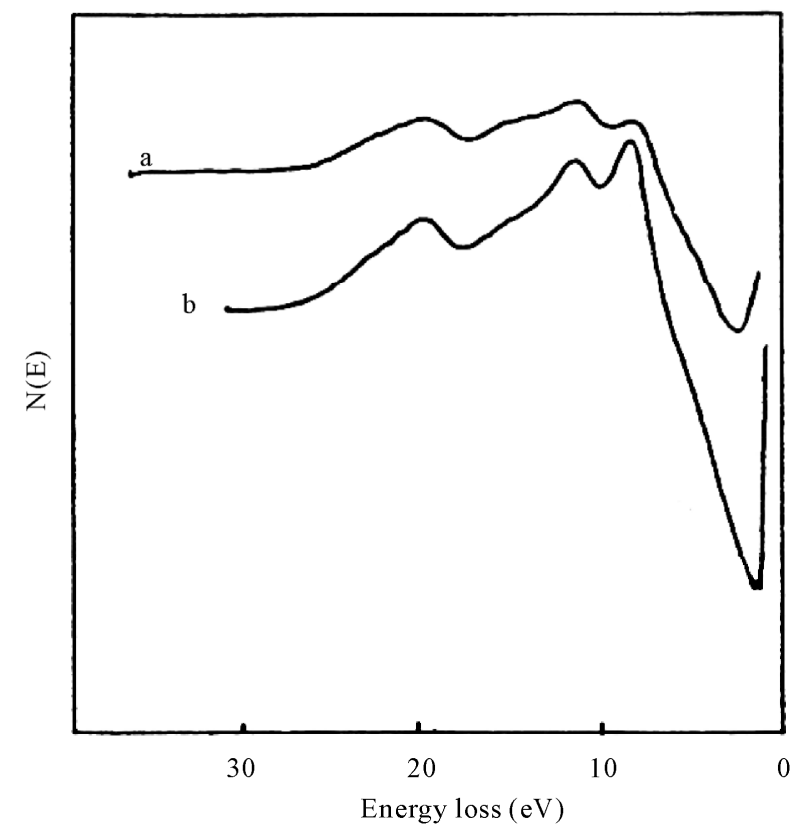

Figure 3. Structure of final state of EELS spectra of InP bombarded by $\mathrm{He}^{+}$ions for different primary energy $\mathrm{Ep}$ : a) $E p=750 \mathrm{eV}$ and b) $E p=500 \mathrm{eV}$.

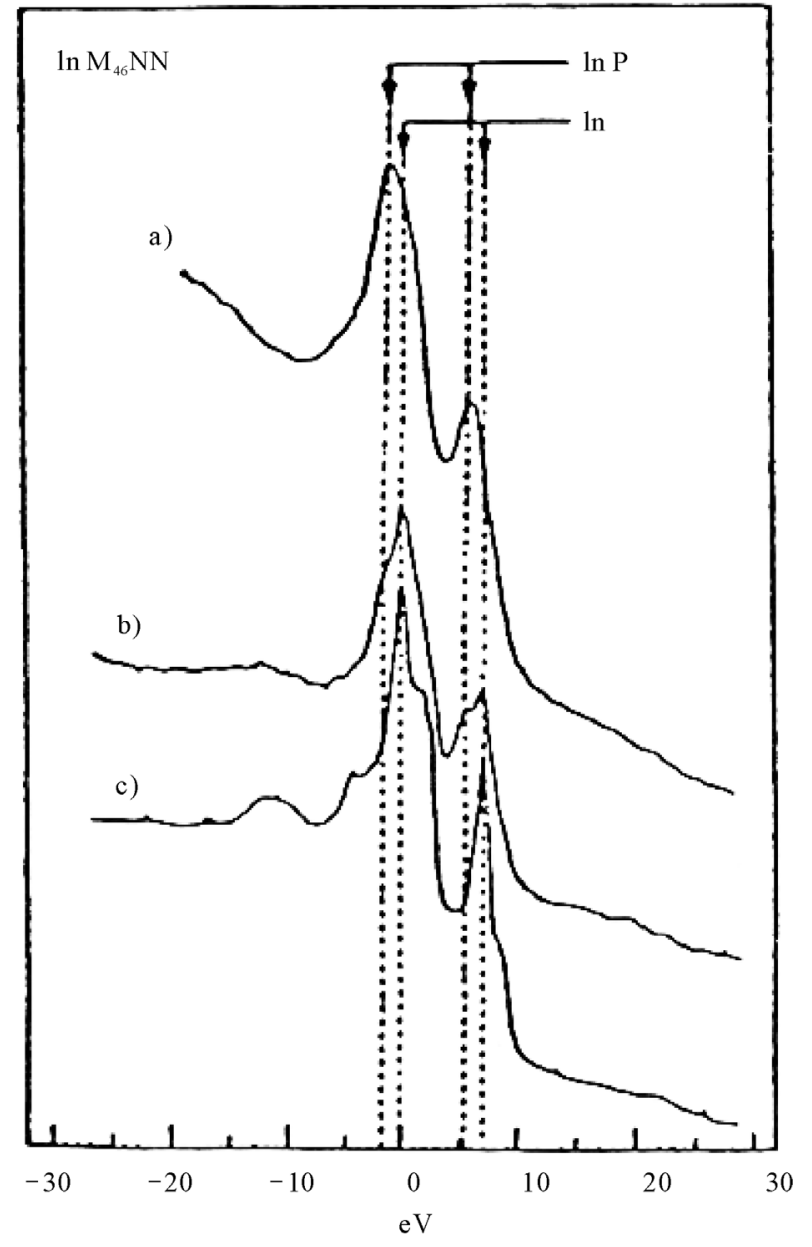

Figure 4. Evolution of In-MNN Auger spectra of InP: a) After introduction of the sample in the UHV chamber, b) After $\mathrm{H}^{+}$ions bombardment and c) pure metallic In sample.

Figure 5. The high reactivity between the chemical elements hydrogen and phosphorus led to a rupture of chemical bonds (In-P) and formation of $\mathrm{PH}$ and $\mathrm{PH}_{3}$ species, which desorbed from the surface.

\subsection{Simulation Method TRIM}

The TRIM simulation method is based on the interaction process between the $\mathrm{Ar}^{+}, \mathrm{He}^{+}$and $\mathrm{H}^{+}$ions and the matter. The ions bombardment is achieved according to the normal incidence with the surface. The effect of ions induces a displacement of atoms of the target with the possibility to form vacancies on irradiated area. Such a process is susceptible to lead to a new arrangement of atoms occurring in the material matrix. We interest to study the interaction mechanism between ions and the InP target. However, our aim is to know also the depth affected by ions. The recorded TRIM spectra are constituted of two main peaks. Disturbed depths, as indicated 


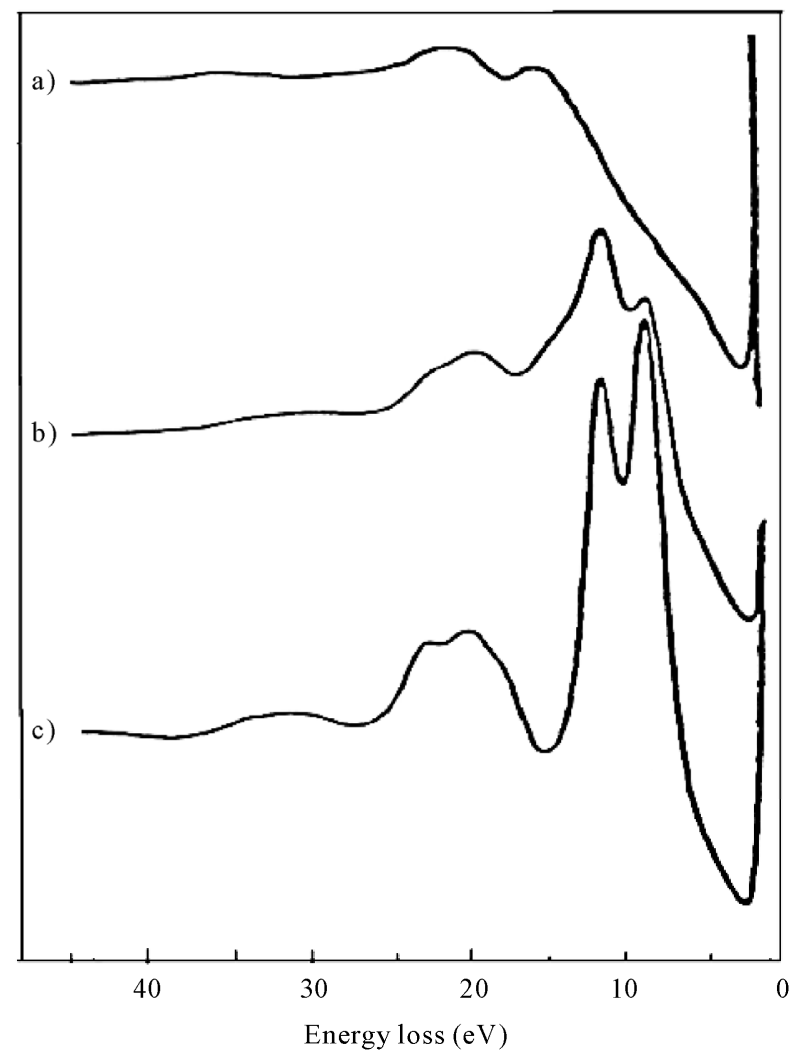

Figure 5. EELS spectra recorded at $1000 \mathrm{eV}$ of InP: a) After introduction of the sample in the UHV chamber, b) After $\mathrm{H}^{+}$ions bombardment and c) pure metallic In sample. by the position of the second peak vary as a function of ions energy. The interaction process between the ions and the target depends on the chemical nature of target, its physical structure and even on the nature and energy of ions. The interaction process occurs first with the outmost layers of the target. The importance of damage due to ions on the target is related to the location of the TRIM peaks. However, the interaction phenomenon ions-matter is complex. It depends on the cross-section as was reported by other authors [24,25] and on other physical parameters. In Figure 6, we give the variation of the depth at which the TRIM second peak appeared as a function of the ions energy.

The curves reflect the effect of the ions irradiation on the bulk of the material. Its linear variation is a good means for indicating the homogeneity of the physical and chemical structure of clean bulk InP compound. We show on the Figure 6 that the $\mathrm{H}^{+}$is penetrated deeply that other ions. This might be explained by its small size comparatively to $\mathrm{He}^{+}$and $\mathrm{Ar}^{+}$ones. On the other hand, the action of ions depends on the physical properties related to atomic displacement and relaxation phenomenon of the target. This lead to a mean depth of ions calculated as a function of ions energy as shown on Figure 7.

\section{Conclusions}

Owing to the analysis techniques such as AES and EELS, we show that the substitute of $\mathrm{Ar}^{+}$ions by a small tall ions like $\mathrm{He}^{+}$or $\mathrm{H}^{+}$to clean the $\mathrm{InP}(100)$ surface is not

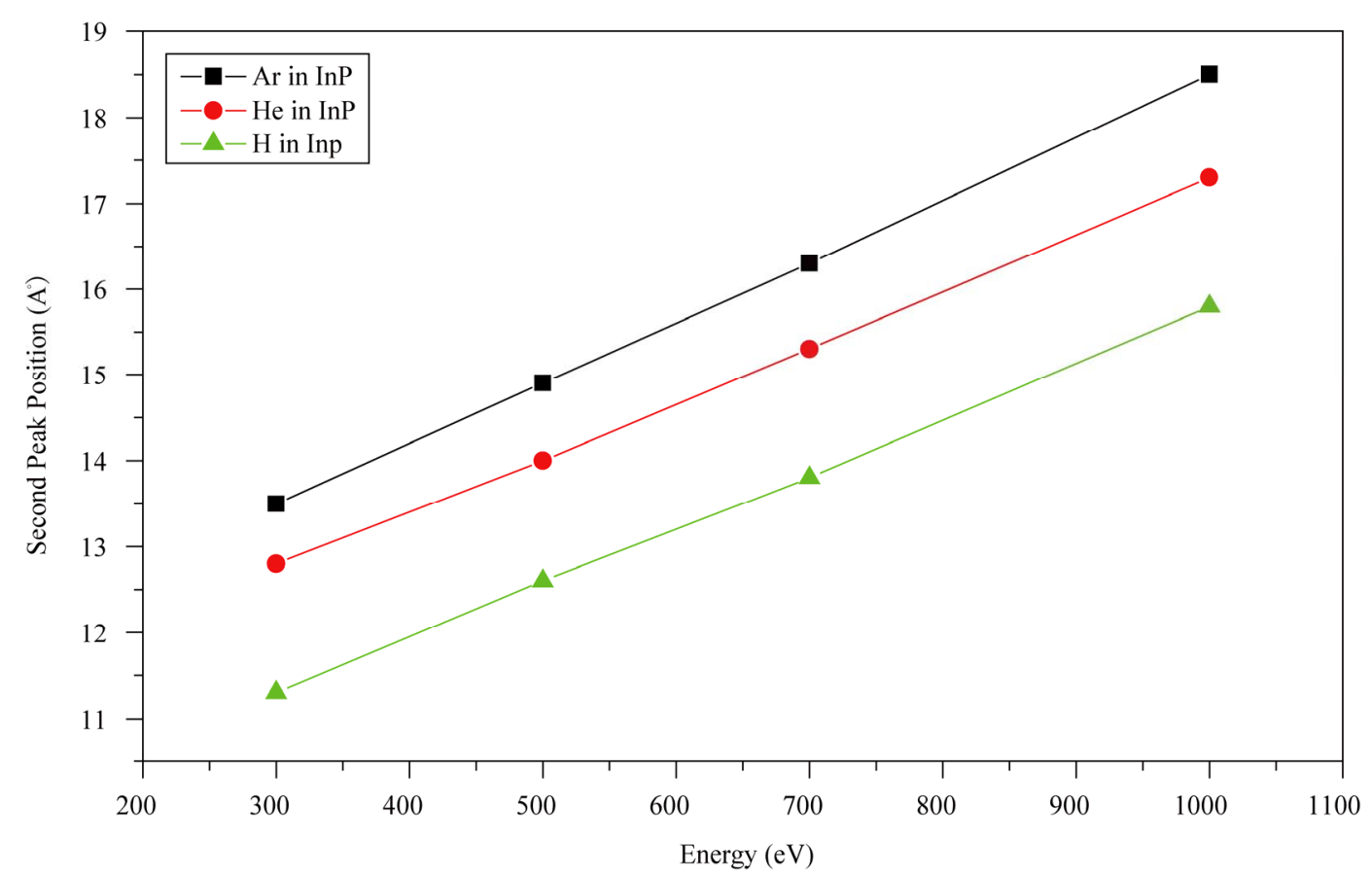

Figure 6. Variation of the depth at which appears the maxima of the TRIM second peak as a function of $\mathrm{H}^{+}$; $\mathrm{He}^{+}$and $\mathrm{Ar}^{+}$ions energy. 


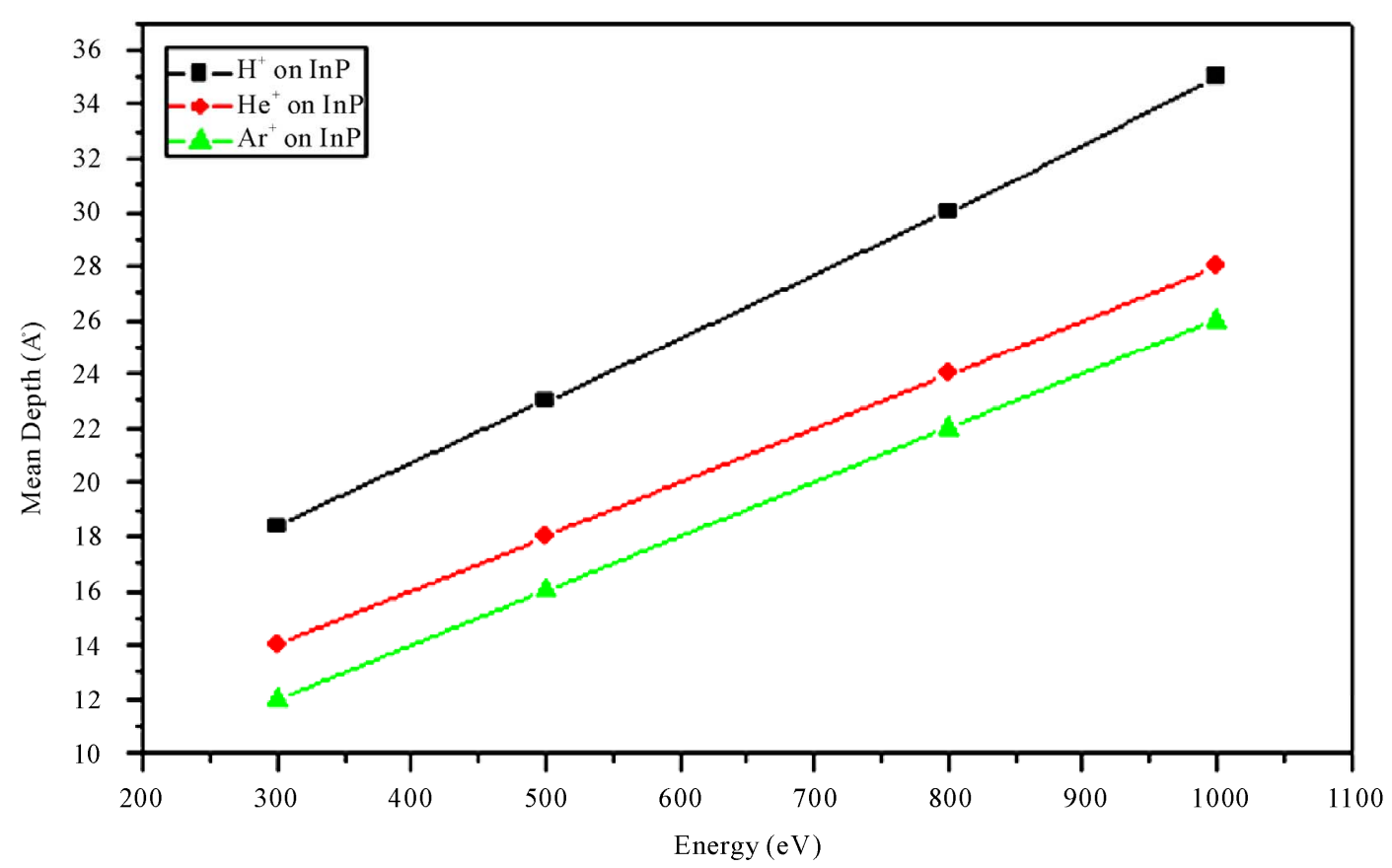

Figure 7. Variation of the mean depth calculated by TRIM simulation method as a function of $\mathrm{H}^{+}$; $\mathrm{He}^{+}$and $\mathrm{Ar}^{+}$ions energy.

advantageous. Indeed, the use of $\mathrm{He}^{+}$and $\mathrm{H}^{+}$ions allow to remove carbon and oxygen contaminants but induces damaged and no stoichiometric surface. There appears an excess of metallic indium distributed on the top of the surface with desorption of phosphorus.

The association of the simulation method TRIM to EELS and AES reveals the different interactions in bulk between the ions and the InP target. The $\mathrm{H}^{+}$ions interaction process affects a higher mean depth than $\mathrm{He}^{+}$and $\mathrm{Ar}^{+}$ones. However, the damaged depth caused on the target InP by the $\mathrm{Ar}^{+}$ions is more important than $\mathrm{H}^{+}$and $\mathrm{He}^{+}$ones. The combination of AES, EELS and TRIM constitutes a good tool to study the compositional aspect of disturbed depths by the $\mathrm{Ar}^{+}, \mathrm{He}^{+}$and $\mathrm{H}^{+}$ions irradiating the InP compound.

\section{REFERENCES}

[1] M. Yamada, A. K. Wahi, T. Kendelewicz and W. E. Spicer, "Schottky Barrier Formation on InP(110) Passivated with One Monolayer of Sb," Applied Surface Science, Vol. 56-58, Part 1, 1992, pp. 325-329. doi:10.1016/0169-4332(92)90251-R

[2] B. Sautreuil, P. Viktorovich and R. Blanchet, "Evidence for Interfacial Defects in Metal-Insulator-InP Structures Induced by the Insulator Deposition," Journal of Applied Physics, Vol. 57, 1985, pp. 2322-2324. doi:10.1063/1.334335

[3] C. Jardin, D. Robert, B. Achard, B. Gruzza and C. Pariset, "An AES and EELS Study of InP(100) Surface Subjected to Argon Ion Bombardment," Journal of Surface and In- terface Analysis, Vol. 10, No. 6, 1987, pp. 301-309. doi:10.1002/sia.740100606

[4] A. Ouerdane, M. Bouslama, M. Ghaffour, A. Abdellaoui, K. Hamaida, Z. Lounis, Y. Monteil, N. Berrouachedi and A. Ouhaibi, "Study by EELS and EPES of the Stability of InPO4/InP System," Journal of Applied Surface Science, Vol. 254, No. 2, September 2008, pp. 7394-7399. doi:10.1016/j.apsusc.2008.05.345

[5] S. Tizi, Z. Benamara, M. Chellali, A. Taibi, B. Gruzza, S. Merle and C. Robert, "Effect of InSb Buffer Layer in MIS Structures Based on InP," Journal Vacuum, Vol. 62, No. 4, June 2001, pp. 315-322. doi:10.1016/S0042-207X(00)00427-9

[6] N. I. Plusnin, "Application of AES and EELS for Surface/ Interface Characterization," Journal of Electron Spectroscopy and Related Phenomena, Vol. 137-140, 2004, pp. 161-164. doi:10.1016/j.elspec.2004.02.091

[7] M. Ghaffour, M. Bouslama, Z. Lounis, A. Nouri, C. Jardin, Y. Monteil and H. Dumont, "The Effect of Heating on InGaAs/InP(100) and InPO4/InP(100), Journal of Electron Spectroscopy and Related Phenomena, Vol. 134, No. 1, January 2004, pp. 81-85. doi:10.1016/j.elspec.2003.10.001

[8] A. Abdellaoui, M. Ghaffour, A. Ouerdane, K. Hamaida, Y. Monteil, N. Berrouachedi, Z. Lounis and M. Bouslama, "AES, EELS and TRIM Investigation of InSb and InP Compounds Subjected to Ar+ Ions Bombardment," Journal of Applied Surface Science, Vol. 254, No. 13, April 2008, pp. 4024-4031. doi:10.1016/j.apsusc.2007.12.038

[9] Z. Lounis, M. Bouslama, N. Berrouachedi, C. Jardin, L. Auvray, A. Abdellaoui, A. Ouerdane and M. Ghaffour, "Study by AES and EELS Spectroscopies of Antimony 
and Phosphorus Evaporated on Massive Indium and on Cleaned InP," Journal Vacuum, Vol. 82, No. 5, January 2008, pp. 529-534. doi:10.1016/j.vacuum.2007.08.002

[10] A. Nouri, Z. Lounis, A. Ouerdane, M. Ghaffour, M. Bouadi, H. Dumont, L. Auvray and M. Bouslama, "The Behaviour of Ternary Compounds InGaAs and GaAsN Subjected to Electron Irradiation," Journal Vacuum, Vol. 81, No. 8, March 2007, pp. 979-985. doi:10.1016/j.vacuum.2006.12.001

[11] M. Bouslama, Y. Monteil, G. Younes, C. Jardin and M. Ghamnia, "Effects of the Electron Beam on InP(100)," Journal Vacuum, Vol. 47, No. 1, January, 1996, pp. 27-33. doi:10.1016/0042-207X(95)00173-5

[12] C. Jardin, D. Robert, B. Achard, B. Gruzza and C. Pariset, "Some Practical Applications of Elastic Peak Electron Spectroscopy," Journal of Analytical Electron Spectroscopy, Vol. 19, No. 1-12, 1992, pp. 5-8.

[13] B. M. Duc, C. Jardin, J. P. Gauthier and P. Michel, “A Low-Energy Electron Spectrometer Using Concentric Hemispheres and a Grid Retarding Field," Journal of Physics and Instruments, Vol. 12, 1979, pp. 43-49.

[14] D. Gautard, J. L. Laporte, M. Cadoret and C. Pariset, "Ellipsometric Study of Surface Treatments Carried out on (100)InP inside VPE Reactor," Journal of Crystal Growth, Vol. 71, No. 1, January-February 1985, pp. 125131. doi:10.1016/0022-0248(85)90052-1

[15] C. Jardin and M. Bouslama "Electron Energy Loss Spectroscopy at Different Surface Sensitivities," Journal of Microscopy and Electron Spectroscopy, Vol. 13, No. 5, 1988, pp. 395-404.

[16] L. Bideux, Y. O. Metidji, B. Gruzza and V. Matolin, "Study of InP(100) Surface Irradiation by X-Ray Photoelectron Spectroscopy," Surface and Interface Analysis, Vol. 34, No. 1, 2002, pp. 712-715. doi:10.1002/sia.1394

[17] S. Abdellaoui, B. Gruzza, C. Pariset, M. Bouslama, C. Jardin and D. Robert, "Study of Sb Condensation on InP(100) Substrates Previously Cleaned by Low Energy Ar+ Ion Beam," Journal of Surface Science Letters, Vol.
L21, 1989, pp. 208-215.

[18] M. Bouslama, Z. Lounis, M. Ghaffour, M. Ghamnia and C. Jardin, "The Study of InPO4/InP(100) by EELS and AES," Journal Vacuum, Vol. 65, No. 2, April 2002, pp. 185-189. doi:10.1016/S0042-207X(01)00480-8

[19] M. Bouslama, M. Ghamnia, B. Gruzza, F. Miloua and C. Jardin, "AES and EELS Analysis of the Interaction between Phosphorus and Metallic Indium," Journal of Electron Spectroscopy and Related Phenomena, Vol. 68, May 1994, pp. 377-382. doi:10.1016/0368-2048(94)02137-6

[20] M. Bouslama, 'Etude par spectroscopies d'électrons Auger et de pertes d'énergie des semi-conducteurs $\mathrm{InP}(100)$ et InSb(100)," Ph.D. Dissertation, University of Claude Bernard, LyonI, France, 1989.

[21] A. Porte, B. Gruzza, C. A. Bondot, L. Bideux, C. Jardin and G. Gergely, "The Interaction of Hydrogen with the InP(100) Substrates Studied by AES, EPES and EELS," Journal of Electron Spectroscopy and Related Phenomena, Vol. 68, May 1994, pp. 391-397. doi:10.1016/0368-2048(94)02139-2

[22] J. A. Schaefer, "Hydrogen Interaction with Semiconductor Surfaces," Journal of Surface Science, Vol. 178, No. 1-3, December 1986, pp. 90-95. doi:10.1016/0039-6028(86)90284-0

[23] F. Proix, O. M'hamedi, M. Cherchour and C. A. Sebenne, "Study of the Interaction of Atomic and Ionized Hydrogen with Cleaved Surfaces of InP(110)," Journal Le vide, Les couches minces, Vol. 41, 1986, pp. 189-195.

[24] L. Nasdala, M. Wenzel, M. Andrut, R. Wirth and P. Blaun, "The Nature of the Radiohaloes in Biotite: Experimental Studies and Modelling," Mineralogical Society of America, Vol. 86, No. 4, 2001, pp. 498-512.

[25] W. Moller and S. Mukhrjee, "Radiation Effects and Defects in Solids: Incorporating Plasma Science and Plasma Technology," Computer Simulation of Ion-Assisted Thin Film Deposition, Vol. 141, No. 1-4, 1997, pp. 73-81. 